\title{
Calculations of Escape Probabilities of Nuclear Radiations from Simplified Model Sources
}

\author{
Chizuo MORI \\ Department of Nuclear Engineering, Faculty of Engineering, \\ Nagoya University, Nagoya, Japan \\ Received July 16, 1974
}

\begin{abstract}
Escape probabilities of radiations from slab and spherical homogeneous sources covered with shields are calculated for three different absorption characteristics of radiations; step functionally decreasing absorption characteristic, linearly decreasing one and exponentially decreasing one. When the probabilities are not expressed in elementary functions, numerically calculated results are given in figures.
\end{abstract}

\section{Introduction}

There are many papers on the calculations of absorption of nuclear radiations emitted from a radioisotope source by source itself or by an external shielding absorber ${ }^{1) \sim 4)}$. They are written mainly on $\gamma$-ray absorptions for sources having various shapes. For $\beta$ rays $^{5)}$, calculation was performed under the assumption that they have exponential absorption characteristic like $\gamma$-rays. Selfabsorptions of radiations which show other absorption characteristics such as $\alpha$-particles and electrons are not treated of. Also, calculations for $\gamma$-rays were done mainly for flux which was particle flux density and seldom for current which was normal component of radiations to a plane at a measuring point.

It is sometimes necessary to estimate selfabsorptions of $\mathrm{K}$ and $\mathrm{L}$ Auger electrons, $\mathrm{X}$ rays and $\alpha$-particles in $2 \pi$ or $4 \pi$ geometry of radiation measurement, when these radiation sources are put in $2 \pi$ or $4 \pi$ counter. Then, under the simplifications of absorption characteristics of these radiations, probabilities of the escape of radiations from sources were calculated on homogeneous sources of two kinds of shapes, slab and sphere.

\section{Absorption characteristics}

Relation between the thickness of a slab absorber and the transmitted fraction of radiations which are incident normal to the absorber surface, that is absorption characteristic of radiations, depends on the kind of radiations. Here they are classified simply to the following three.

The first is step functionally decreasing absorption characteristic like, for example, $\alpha$-particles. The second is exponentially decreasing one. For comparatively low energy X-rays, build up effect due to scattered radiations can be neglected. The final is linearly decreasing one, which is the intermediate characteristic between the two mentioned above. There are not such radiations which show exactly this characteristic. But approximately the following two can be considered. One is the case in which it is enough to take into account the first two terms in the expansion series for exponential absorption characteristic function. The other is the case for low energy monoenergetic electrons as shown experimentally by Williams ${ }^{6}$ ) and Young ${ }^{7}$. In the first approximation, it can be considered to be linearly decreasing absorption characteristic as Young concluded that transmitted fraction of monochromatic electrons with energies between 2.5 and $10 \mathrm{keV}$ decreases approximately linearly with the fractional range covered by the primary beam.

In two types of sources, slab and sphere as mentioned in the introduction, escape probabilities of radiations are calculated 
for the three kinds of absorption characteristic. The penetration ranges $R$ for $\alpha$ particles and electrons are simply considered here not to depend on materials when the ranges are expressed in mass thickness and the atomic numbers of the materials do not differ so much. Thickness or length $t, T$, $s, l$ and radius $a$ etc. are expressed in optical length. Mass absorption coefficient of electromagnetic radiations and density of materials are written by $\mu$ and $\rho$, respectively.

\section{Escape probabilities for slab source}

A homogeneous slab source with thickness of $t$, which is covered with a shielding plate with thickness of $T$, as shown in Fig. 1 is considered. Escape probability $P$ is the ratio of the number of radiations emitted from the surface of a shielding plate, without suffering self-absorption in the source itself and the absorption by a shielding plate, to the number of radiations emitted in $2 \pi$ direction from radioactive atoms.

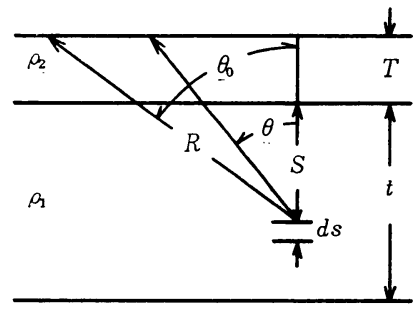

Fig. 1 Slab source with the thickness of $t$ covered with shielding plate of thickness $T$.

3.1 Step functionally decreasing absorption characteristic

Simply, $P$ is calculated as follows, referring to Fig. 1.

When $\rho_{1} t+\rho_{2} T \leqslant R$

$P=\frac{1}{t} \int_{0}^{t}\left(1-\cos \theta_{0}\right) d s=1$

$-\left(\rho_{1} t / 2+\rho_{2} T\right) / R$

When $\rho_{1} t+\rho_{2} T \geqslant R$

$P=\left(1-\rho_{2} T / R\right)\left(R-\rho_{2} T\right) / 2 \rho_{1} t$
3.2 Linearly decreasing absorption characteristic

Escape probability $P$ is given by the integral of the solid angle ratio multiplied by absorption term, $1-\left(\rho_{1} s+\rho_{2} T\right) / R \cos \theta$.

When $\rho_{1} t+\rho_{2} T \leqslant R$,

$$
\begin{aligned}
P= & 1-\frac{1}{R}\left(\frac{\rho_{1} t}{2}+\rho_{2} T\right)\left(\frac{3}{2}-\ln \frac{\rho_{1} t+\rho_{2} T}{R}\right) \\
& -\frac{\rho_{2}^{2} T^{2}}{2 R \rho_{1} t} \ln \frac{\rho_{2} T}{R}
\end{aligned}
$$

If the source has a backing plate, having backscattering coefficient $f_{B}$, with infinit thickness,

$$
\begin{aligned}
P= & 1-\frac{1}{R}\left(\frac{\rho_{1} t}{2}+\rho_{2} T\right)\left(\frac{3}{2}-\ln \frac{\rho_{1} t+\rho_{2} T}{R}\right) \\
& -\frac{\rho_{2}^{2} T^{2}}{2 R \rho_{1} t} \ln \frac{\rho_{2} T}{R}+\left\{1-\frac{\rho_{1} t}{2 R}\left(\frac{3}{2}-\ln \frac{\rho_{1} t}{R}\right)\right\} \\
& \cdot f_{B}\left\{1-\frac{\rho_{1} t+\rho_{2} T}{R_{B}}\left(1-\ln \frac{\rho_{1} t+\rho_{2} T}{R_{B}}\right)\right\} \quad
\end{aligned}
$$

where $R_{B}$ is the range of backscattered radiations.

When $\rho_{1} t+\rho_{2} T \geqslant R$,

$$
P=\frac{R-\rho_{2} T}{2 \rho_{1} t}\left\{\frac{1}{2}-\frac{\rho_{2} T}{R}\left(\frac{3}{2}+\frac{\rho_{2} T}{R-\rho_{2} T} \ln \frac{\rho_{2} T}{R}\right)\right\}
$$

3.3 Exponentially decreasing absorption characteristic

Mass absorption coefficient of a source slab and a shielding plate are expressed by $\mu_{1}$ and $\mu_{2}$, respectively. Then,

$$
\begin{gathered}
P=\frac{1}{t} \int_{0}^{t} d s \int_{0}^{\pi / 2} \sin \theta \exp \left\{-\left(\mu_{1} s+\mu_{2} T\right) \sec \theta\right\} \\
\cdot d \theta=\frac{1}{\mu_{1} t}\left\{E_{3}\left(\mu_{2} T\right)-E_{3}\left(\mu_{1} t+\mu_{2} T\right)\right\} \quad(6)
\end{gathered}
$$

Where

$$
E_{n}(x)=\int_{1}^{\infty} t^{-n} \exp (-x t) d t
$$

The result for $T=0$ is same to the equation $^{3)}$ shown already by Price, et al. for current, not for flux, at a point exterior to a slab source. Numerical values of $E_{3}(x)$ are given in ordinary numerical tables ${ }^{8)}$.

\section{Escape probabilities for spherical source}

A homogeneous spherical source of radius $a$ with shielding shell of thickness $T$ is considered here, as shown in Fig. 2. In this case, $P$ is the ratio of radiations emitted 
from the surface of the shell to the total radiations emitted from radioactive atoms in $4 \pi$ direction.

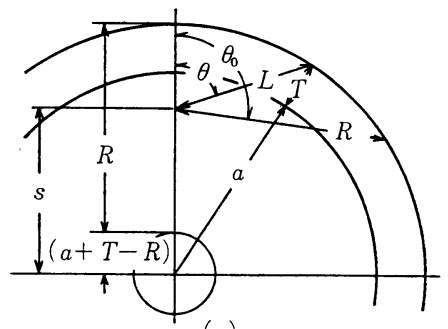

(a)

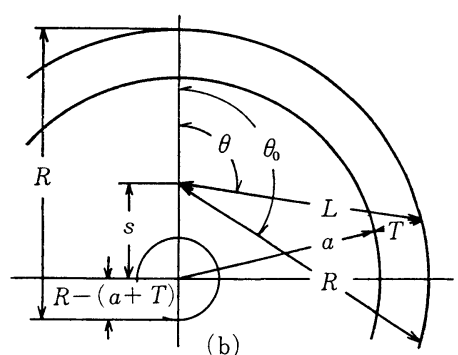

(b)

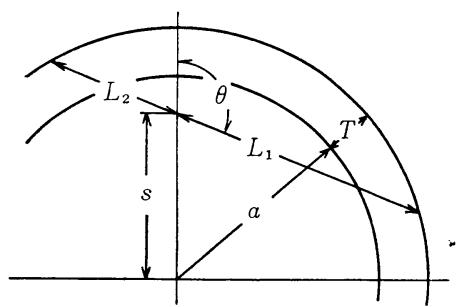

(c)

Fig. 2 Spherical source with the radius of $a$ covered with spherical shell shield of thickness $T$;

(a) $R \leqslant a+T, \quad$ (b) $a+T \leqslant R \leqslant 2 a$ $+T$, and (c) $2 a+T \leqslant R$.

4.1 Step functionally decreasing absorption characteristic

When the densities of source and shieldIing shell are equal, the following relation is obtained, referring to Fig. 2 (a) and (b), $\cos \theta=\left\{(a+T)^{2}-R^{2}-s^{2}\right\} / 2 s R$

then,

$$
\begin{aligned}
P= & \frac{1}{4 \pi a^{3} / 3} \int_{a+T-R}^{a} 4 \pi s^{2} \frac{1}{2}(1-\cos \theta) d s \\
& =\frac{3 R}{4 a}\left\{1-\frac{1}{12}\left(\frac{R}{a}\right)^{2}+\left(1-\frac{2 a}{R}\right) \frac{T}{a}\right. \\
& +\left(\frac{1}{2}-\frac{2 a}{R}+\frac{a^{2}}{R^{2}}\right)\left(\frac{T}{a}\right)^{2}+\frac{a}{R}\left(\frac{a}{R}-\frac{2}{3}\right)
\end{aligned}
$$

$$
\left.\cdot\left(\frac{T}{a}\right)^{3}+\frac{1}{4}\left(\frac{a}{R}\right)^{2}\left(\frac{T}{a}\right)^{4}\right\}
$$

If $T=0$ and $a=R, P$ is equal to $11 / 16$

4.2 Linearly decreasing absorption characteristic

When the densities of a source and shielding shell are equal, the following equations are obtained.

When $R \leqslant a+T$,

$$
\begin{aligned}
P= & \frac{1}{4 \pi a^{3} / 3} \int_{a+T-R}^{a} d s \int_{0}^{\theta_{0}} 2 \pi s^{2}\left(1-\frac{L}{R}\right) \sin \theta d \theta \\
& =\frac{3}{2} A^{3} \int_{1-1 / A B}^{1 / A} x^{2}\left[1-\cos \theta_{0}-\frac{A B}{2}\right. \\
& \cdot\left\{1-x \sin ^{2} \theta_{0}-\left(1-x^{2} \sin ^{2} \theta_{0}\right)^{1 / 2} \cos \theta_{0}\right. \\
& -\frac{1-x^{2}}{x} \ln \mid\left\{x \cos \theta_{0}+\left(1-x^{2} \sin ^{2} \theta_{0}\right)^{1 / 2}\right\} \\
& /(1+x) \mid\}] d x
\end{aligned}
$$

Where $L=\left\{(a+T)^{2}-s^{2} \sin ^{2} \theta\right\}^{1 / 2}-s \cos \theta$,

$$
\begin{aligned}
\theta_{0}=\cos ^{-1}\left\{\frac{A B}{2 x}\left(1-x^{2}-\frac{1}{A^{2} B^{2}}\right)\right\}, \\
\quad A=1+\frac{T}{a}, \quad B=\frac{a}{R}, \text { and } \quad x=\frac{s}{a+T} .
\end{aligned}
$$

Although some terms in Eq. (8) are still able to be integrated with respect to $x$, they are remained in integrand for numerical calculation together with the logarithmic term using an electronic computer.

When $a+T \leqslant R \leqslant 2 a+T$, the limits of $\theta$ on the integral of absorption function with respect to $\theta$ are different for $x \leqslant R-(a+T)$ and for $x \geqslant R-(a+T)$, as shown in Fig. 2 (b), then

$$
\begin{aligned}
P= & \frac{1}{4 \pi a^{3} / 3}\left\{\int_{\dot{R}-(a+T)}^{a} \int_{0}^{\theta_{0}} 2 \pi s^{2}\left(1-\frac{L}{R}\right) \sin \theta d \theta d s\right. \\
& +\int_{0}^{R-(a+T)} \int_{0}^{\pi} 2 \pi s^{2}\left(1-\frac{L}{R}\right) \sin \theta d \theta d s \\
& =\frac{3}{2} A^{3} \int_{1 / A}^{1 / A} x^{2}\left[1-\cos \theta_{0}-\frac{A B}{2}\right. \\
& \cdot\left\{1-x \sin ^{2} \theta_{0}-\left(1-x^{2} \sin ^{2} \theta_{0}\right)^{1 / 2} \cos \theta_{0}\right. \\
& \left.\left.-\frac{1-x^{2}}{x} \ln \left|\frac{x \cos \theta_{0}+\left(1-x^{2} \sin \theta_{0}\right)^{1 / 2}}{1+x}\right|\right\}\right] \\
& \cdot d x
\end{aligned}
$$

where $L, \theta_{0}, A, B$ and $x$ are same to those for the case $R \leqslant a+T$.

When $2 a+T \leqslant R$, the sum $P^{\prime}$ of the probability that the radiations emitted in $L_{1}$ direction at a point $H$, in Fig. 2(c), escape 
from the shield surface and the same probability for radiations emitted in $L_{2}$ direction which is opposite to $L_{1}$ is expressed as

$$
\begin{aligned}
P^{\prime}= & 1-\frac{L_{1}}{R}+1-\frac{L_{2}}{R} \\
& =2\left[1-\frac{\left\{(a+T)^{2}-s^{2} \sin ^{2} \theta\right\}^{1 / 2}}{R}\right]
\end{aligned}
$$

Then, for all directions emitted in a sphere source,

$$
\begin{aligned}
P= & \frac{1}{4 \pi a^{3} / 3} \int_{0}^{a} \int_{0}^{\pi / 2} 2 \pi s^{2} P^{\prime} \sin \theta d \theta d s \\
& =1-\frac{3}{8} A B\left[1+A^{2}+\left\{A\left(1-\frac{A^{2}}{2}\right)\right.\right. \\
& \left.\left.-\frac{1}{2 A}\right\} \ln \frac{1+1 / A}{1-1 / A}\right]
\end{aligned}
$$

where $A$ and $B$ are same to those for the case $R \leqslant a+T$.

$$
\text { If } T=0, P=1-\frac{3 a}{4 R}
$$

The values of $P$ and $1-P$ as a function of $a / R$ were obtained by numerical calculations for various values of $T / a$. Some of the results are shown in Fig. 3.

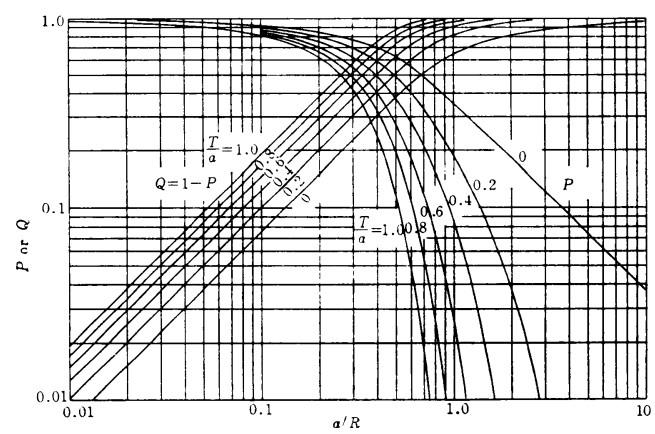

Fig. 3 Escape probability $P$ and absorption one $1-P$ of radiations having linearly decreasing absorption characteristic for a spherical source with the radius of $a$ covered with spherical shell shield with the thickness of $T . R$ is the range of radiations.

\subsection{Exponentially decreasing absorption characteristic}

On the shielding of $\gamma$-rays, which show exponentially decreasing absorption characteristic, emitted from a spherical source, there are already many papers. For example, they treated of flux at a point outside a spherical source ${ }^{1,2)}$, flux at a point through a slab shield ${ }^{1}$ and spherical shell shield ${ }^{21}$ and current at a point outside a spherical source ${ }^{3)}$. But there seems to be no papers on current at a point through spherical shell shield. When escape probability of radiations emitted from a spherical source is known, current at a distance $d$ from the center of the source is obtained by dividing the escape probability by $4 \pi d^{2}$. Then here, escape probability of radiations from a spherical source with shell shield is calculated.

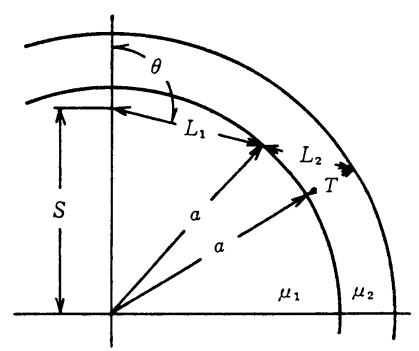

Fig. 4 Spherical source with absorption coefficient of $\mu_{1}$ covered with spherical shell shield of the coefficient $\mu_{2}$.

Since absorption coefficient $\mu_{1}$ of a source and that $\mu_{2}$ of shielding shell are generally different, radiation path $L_{1}$ in a source and path $L_{2}$ in shielding shell, as shown in Fig. 4 should be written separately;

$$
\begin{aligned}
L_{1}= & \left(a^{2}-s^{2} \sin ^{2} \theta\right)^{1 / 2}-s \sin \theta \\
L_{2}= & \left\{a^{2}-s^{2} \sin ^{2} \theta+T(2 a+T)\right\}^{1 / 2} \\
& -\left(a^{2}-s^{2} \sin ^{2} \theta\right)^{1 / 2}
\end{aligned}
$$

Then,

$$
\begin{aligned}
P= & \frac{1}{4 \pi a^{3} / 3} \int_{0}^{a} \int_{0}^{\pi} 2 \pi s^{2} \sin \theta \exp \left(-\mu_{1} L_{1}\right. \\
& \left.-\mu_{2} L_{2}\right) d \theta d s=\frac{3}{2} \int_{0}^{1} \int_{0}^{\pi} X^{2} \sin \theta \exp \\
& \cdot\left[-\mu_{1} a\left(1-X^{2} \sin ^{2} \theta\right)^{1 / 2}-X \cos \theta\right. \\
& +\left\{1-X^{2} \sin ^{2} \theta+2 Y+Y^{2}-\left(1-X^{2}\right.\right. \\
& \left.\left.\left.\cdot \sin ^{2} \theta\right)^{1 / 2}\right\} \mu_{2} / \mu_{1}\right] d \theta d x
\end{aligned}
$$

where $X=s / a$ and $Y=T / a$.

The values of $P$ and $1-P$ as a function of $\mu_{1} a$ for various values of $\mu_{2} / \mu_{1}$ and $T / a$ were obtained by numerical calculations. The results for $\mu_{1}=\mu_{2}$ are shown in Fig. 5 .

If $T=0$ and $\mu_{1} a \ll 1$, Eq. (13) comes to be same to Eq. (11) and $P$ is expressed simply by 


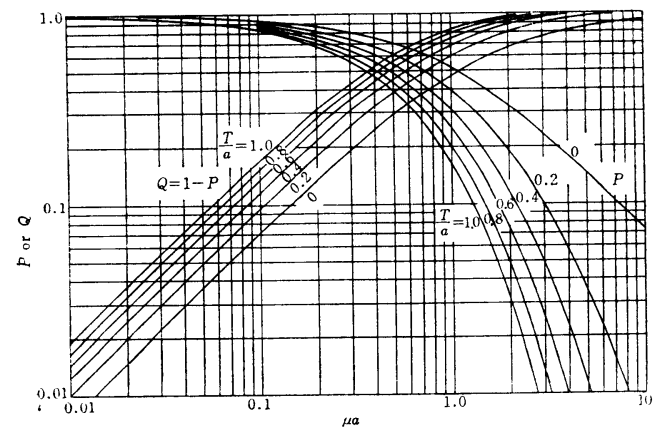

Fig. 5 Escape probability $P$ and absorption one $1-P$ of radiations having exponentially decreasing absorption characteristic for a spherical source with the radius of $a$ and absorption coefficient $\mu_{1}$, covered with spherical shell shield with the thickness of $T$ and absorption coefficient $\mu_{2}$.

$$
P=1-3 \mu a / 4
$$

\section{Conclusions}

The calculated results using step functionally decreasing absorption characteristic for $\alpha$-particles and exponentially decreasing absorption characteristic for $\mathbf{X}, \gamma$-rays are able to be used to a satisfactory degree of accuracy to estimate the absorption of these radiations. The results using linearly decreasing absorption characteristic are also useful to estimate the absorption of $\mathrm{X}, \gamma^{-}$ or $\beta$-rays from a very thin source, since it is enough to take into account the first two terms in the expansion series for exponential absorption characteristic function; but, on the usage of the results for the estimation of the absorption of low energy monochromatic electrons, the accuracy will be a degree of first approximation due to the complication of the scattering phenomenon.

\section{Acknowledgements}

The author would like to express his thanks to Prof. T. Watanabe for his valuable discussions and also to $\mathrm{Mr}$. H. Noguchi for his assistance in a part of the numerical calculations.

\section{References}

1) R.G. Jaeger, et al.: Engineering Compendium on Radiation Shielding, Vol. 1 p. 363, Springer-Verlag (1968)

2) E.P. Blizard and L.S. Abbott: Reactor Handbook, Vol. 3 part B, p. 128, Interscience Publishers (1962)

3) B.T. Price, C.C. Horton and K.T. Spinnely: Radiation Shielding, p. 212, Pergamon Press (1957)

4) W.R. Dixon: Nucleonics, 8, (4) 68 (1951)

5) H.H. Rossi and R.H. Ellis: Nucleonics, 7,(1) 19 (1950)

6) E.J. Williams: Proc. Roy. Soc. (London) A 130, 310 (1931)

7) J.R. Young: J. Appl. Phys., 28, 524 (1957)

8) For example, V.I. Pagurova: Tables of Exponential Integral p. 4, Pergamon Press (1961)

\title{
要 旨
}

\section{単純な形状の線源における放射線の吸収の計算}

\author{
森 千鶴夫
}

名古屋大学工学部原子核工学教室, 名古屋市千種区不老町

$2 \pi$ あるいは $4 \pi$ の測定条件に㧍いて，板状扰よび球状の均質線源における自己吸収，およびこれ らの線源を囲む遮蔽体による放射線の吸収を計算によって求めた。この場合放射線の吸収特性を単 純化したつぎの 3 種，すなわち $\alpha$ 線のような段階的な吸収特性，低エネルギー単色電子線のような 直線的な吸収特性，および X, $\gamma$ 線のような指数関数的な吸収特性で計算し，結果が初等関数で表 わせない場合には数值計算を行ない図に示した。 